\title{
ESTUDO DA INFLUÊNCIA DAS VARIÁVEIS DE PROCESSO NA FORMAÇÃO DE FILME LÍQUIDO EM LAVADORES VENTURI
}

\author{
A. C. Costa de Lima ${ }^{1}$, L. P. Borges ${ }^{1}$ e V. G. G. Béttega ${ }^{1}$ \\ ${ }^{1}$ Universidade Federal de São Carlos - UFSCar \\ E-mail para contato: anacarolinecostadelima@gmail.com
}

\begin{abstract}
RESUMO - Lavadores Venturi são equipamentos que atuam com alta eficiência na coleta de material na faixa respirável. São basicamente tubos constituídos de três principais partes: a seção convergente, a garganta e o difusor. Neste equipamento, um líquido é injetado na forma de jatos através de orifícios na garganta, virando gotas coletoras de partículas da corrente gasosa. Contudo, durante o processo, uma fração das gotas se deposita nas paredes do equipamento, formando um filme líquido, o qual não contribui para a remoção de contaminantes. Diante disso, avaliou-se as condições experimentais favoráveis a uma menor fração de filme em dois lavadores de secção circular na posição vertical, um com $20 \mathrm{~mm}$ de diâmetro de garganta e outro com 40mm. No caso do lavador de diâmetro $40 \mathrm{~mm}$, notou-se a enorme dependência da velocidade do gás na formação de fração de filme em função da razão L/G. Já para o lavador de diâmetro $20 \mathrm{~mm}$, é perceptível na maioria dos casos a insignificante influência da variação da velocidade do gás na formação de filme líquido em função da razão L/G. Além disso, para esse mesmo lavador as curvas de modo geral apresentam a tendência de diminuição da fração de filme ao se aumentar a razão entre líquido injetado e vazão de gás $(\mathrm{L} / \mathrm{G})$. As menores frações de filme, no caso do lavador maior, ocorrem para a configuração de 6 orifícios, enquanto que para o lavador menor ocorrem na configuração de 4 orifícios.
\end{abstract}

Palavras-chave: Lavador Venturi, fração de filme, orifícios, velocidade do gás, L/G.

\section{INTRODUÇÃO}

A partir do século 18, devido a Revolução Industrial, houve um grande aumento na poluição atmosférica. Este problema é algo bastante frequente principalmente nas grandes cidades, e traz prejuízos para os humanos, animais e plantas. Os poluentes do ar são basicamente diferentes tipos de gases tóxicos e partículas sólidas, os quais podem causar doenças crônicas e reações alérgicas no sistema respiratório (MMA, 2017). Diante dessas circunstâncias entra a utilidade dos lavadores Venturi dentro do ambiente industrial para efetuar o controle do efluente gasoso, principalmente devido à ampliação das políticas de controle da poluição ambiental (MMA, 2014). 
Os lavadores Venturi são equipamentos que atuam com alta eficiência na coleta de material na faixa respirável de 0,5 até $5,0 \mu \mathrm{m}$, possuem poucas restrições de funcionamento e são hábeis no controle de pó e aerossóis (DAHER, 2008). O equipamento basicamente consiste de um tubo que pode ter secção transversal circular ou retangular, sendo constituído de três principais partes: a seção convergente, a garganta e o difusor (GUERRA, 2009).

Neste equipamento, o líquido é injetado na forma de jatos em baixa pressão por meio de orifícios na garganta e quando lá dentro é atomizado por causa da alta velocidade que o gás entra e ainda adquiri ao passar pela garganta, virando gotas coletoras que captam o material particulado principalmente pelo mecanismo de impactação inercial (GONÇALVES, 2000). Contudo, durante o processo, uma fração das gotas acaba se depositando nas paredes do equipamento, formando assim um filme líquido. Este não contribui para a remoção de contaminantes, uma vez que sua área superficial por unidade de volume é menor do que a das gotas (GUERRA, 2010).

Portanto, o estudo da fração de filme, buscando encontrar condições operacionais que a reduza, é importante para o funcionamento eficiente do lavador Venturi. Assim, esse trabalho tem como objetivo analisar o comportamento da fração de filme variando-se as condições experimentais do lavador Venturi, tais como a quantidade de orifícios, a razão L/G e a velocidade do gás.

\section{METODOLOGIA}

Dois lavadores Venturi de secção transversal circular estabelecido na posição vertical, tendo $40 \mathrm{~mm}$ e $20 \mathrm{~mm}$ de diâmetro na garganta $\left(\mathrm{D}_{\text {th) }}\right.$ cada um, foram estudados com respeito à deposição de filme líquido nas paredes, variando-se as condições operacionais tais como: quantidade de orifícios, velocidade do gás, e razão L/G.

O lavador Venturi é um tipo de lavador utilizado na indústria para a limpeza de efluentes gasosos. A Figura 1 mostra a estrutura de um dos lavadores Venturi usados nesse trabalho, o qual também foi usado por GUERRA (2010) em seus experimentos no mestrado. Esse lavador está dividido em cinco seções: convergência, injetores de líquido, garganta, fenda e difusor. $\mathrm{O}$ funcionamento consiste na entrada do gás sujo pela seção de convergência, sendo acelerado pelo estreitamento na garganta e logo em seguida sofrendo desaceleração ao passar pelo difusor. Os injetores de líquido estão localizados no início da região da garganta, enquanto que a fenda fica no final da garganta, sendo responsável por captar a fração de filme líquido que se deposita na parede. A Tabela 1 apresenta algumas dimensões importantes dos lavadores Venturi utilizados nesse experimento, como diâmetro da garganta, diâmetro da entrada e saída, e comprimento das seções convergente e divergente. 
Figura 1 - Foto do lavador Venturi

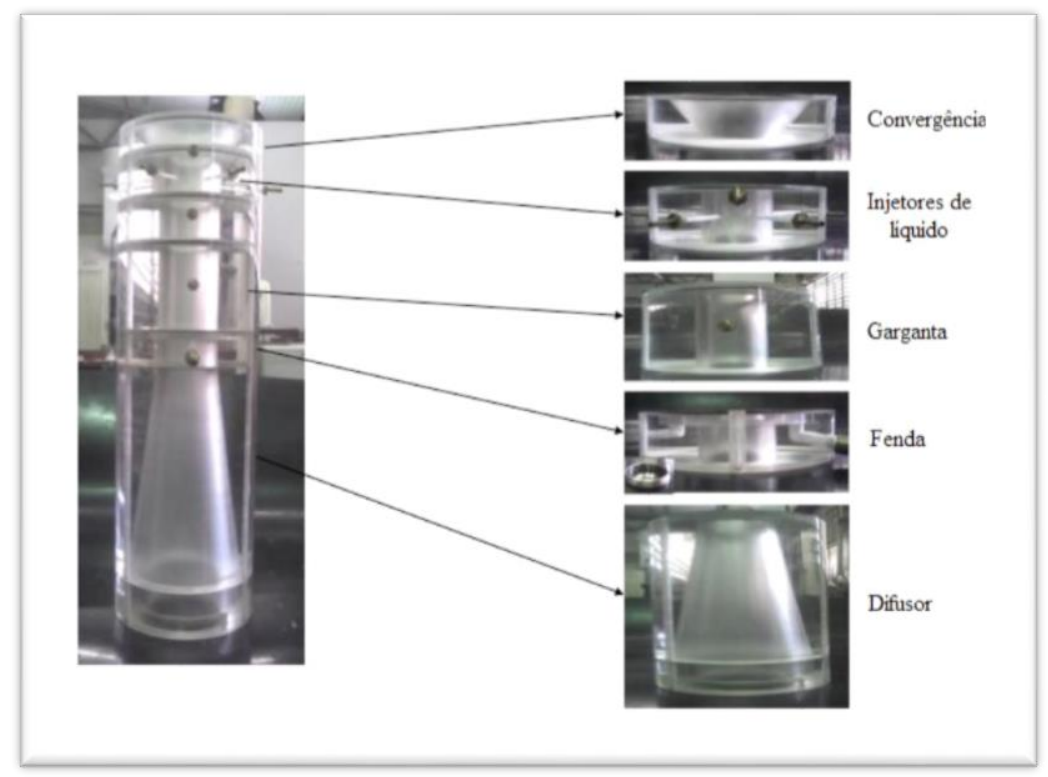

Fonte: GUERRA, A. P., 2010

Tabela 1 - Dimensões dos Lavadores Venturi

\begin{tabular}{|c|c|c|}
\hline Dimensões & Lavador maior $(\mathrm{mm})$ & Lavador menor $(\mathrm{mm})$ \\
\hline Diâmetro de entrada e saída & 76 & 35 \\
\hline Diâmetro da garganta & 40 & 20 \\
\hline Comprimento da seção convergente & 26 & 11 \\
\hline Comprimento da seção divergente & 206 & 86 \\
\hline
\end{tabular}

Fonte: GUERRA, A.P., 2010

A partir dos L/G desejados, as vazões de líquido usadas nesse trabalho foram determinadas por meio da Equação 1, a qual é um rearranjo da equação de VISWANATHAN et al. (1983).

$$
Q_{l}=\frac{l_{\text {máx }} Q_{g} \rho_{g} D_{o r} N_{o r}}{0,1458 \rho_{l} A_{t h}}
$$

Onde $\mathrm{Q}_{1}(\mathrm{l} / \mathrm{h})$ é a vazão de líquido, $1_{\text {máx }}(\mathrm{m})$ a penetração máxima, $\mathrm{p}_{\mathrm{g}}(\mathrm{g} / \mathrm{l})$ a densidade do gás, $\mathrm{D}_{\text {or }}$ diâmetro do orifício $(\mathrm{mm}), \mathrm{N}_{\text {or }}$ número de orifícios, $\mathrm{p}_{1}$ densidade do líquido $(\mathrm{g} / \mathrm{l}), \mathrm{A}_{\text {th }}$ área da garganta $\left(\mathrm{m}^{2}\right)$ e $\mathrm{Q}_{\mathrm{g}}$ vazão do gás $\left(\mathrm{m}^{3} / \mathrm{h}\right)$.

Conforme mostra a Tabela 2 abaixo, com o lavador de diâmetro de garganta maior trabalhou-se com velocidades de gás na garganta $\left(\mathrm{V}_{\text {th }}\right) 26 \mathrm{~m} / \mathrm{s}, 30 \mathrm{~m} / \mathrm{s}$ e $34 \mathrm{~m} / \mathrm{s}$, e para o lavador de garganta menor as velocidades foram $55 \mathrm{~m} / \mathrm{s}, 70 \mathrm{~m} / \mathrm{s}$ e $85 \mathrm{~m} / \mathrm{s}$. No âmbito de cada velocidade, variou-se o L/G em 0,5, 0,7 e 0,9. Ademais, foram considerados os conjuntos de 4 e 6 orifícios de injeção de líquido. 
Tabela 2 - Condições Experimentais

\begin{tabular}{|c|c|c|c|}
\hline $\begin{array}{c}\text { Diâmetro da } \\
\text { garganta }(\mathrm{mm})\end{array}$ & $\begin{array}{c}\text { Velocidade do gás } \\
\text { na garganta }(\mathrm{m} / \mathrm{s})\end{array}$ & L/G & $\begin{array}{c}\text { Quantidade de } \\
\text { orifícios }\end{array}$ \\
\hline \multirow{2}{*}{20} & 55 & & \\
& 70 & 0,5 & 4 \\
40 & 26 & 0,7 & 6 \\
& 30 & 0,9 & \\
\hline \multirow{2}{*}{40} & & \\
\hline
\end{tabular}

\section{RESULTADOS E DISCUSSÃO}

A Figura 2 mostra a formação de filme líquido ao se variar a velocidade do gás, a quantidade de orifícios de injeção e a razão L/G, para os dois lavadores Venturi estudados, um de $20 \mathrm{~mm}$ de garganta e outro de $40 \mathrm{~mm}$.

Figura 2 - Fração de filme em função da razão $\mathrm{L} / \mathrm{G}\left(\mathrm{L} / \mathrm{m}^{3}\right)$. (a) lavador maior 4 orifícios (b) lavador maior 6 orifícios (c) lavador menor 4 orifícios (d) lavador menor 6 orifícios.

No caso do lavador com diâmetro de garganta maior ( $D_{\text {th }} 40 \mathrm{~mm}$ ), as curvas para configuração de injeção de líquido por 4 orifícios, Figura 2 (a), apresentaram comportamento diferente ao das curvas obtidas para a configuração de 6 orifícios, Figura 2 (b). Isso pode ter ocorrido visto que para uma mesma vazão de líquido, um número maior de orifícios faz com que os jatos de líquido penetrem menos no interior do equipamento, ocasionando diferentes frações de líquido depositadas nas paredes. Nesse âmbito, GUERRA (2010) observou que para baixas e altas penetrações, a fração de filme era alta, havendo assim um ponto de mínima formação de filme nesse intervalo. Além disso, tanto na Figura 2 (a) quanto na Figura 2 (b), foi possível perceber a enorme dependência da velocidade do gás, visto que a mudança na velocidade do gás altera consideravelmente o comportamento da fração de filme em função da razão L/G, o que também está de acordo com o trabalho de GUERRA (2010).

No caso do lavador de garganta menor $\left(D_{\text {th }}=20 \mathrm{~mm}\right)$, como pode ser visto na Figura 2 (c) e (d), a fração de filme diminui com o aumento do $\mathrm{L} / \mathrm{G}$ considerando-se todas as velocidades e quantidades de orifícios estudadas. Os resultados de GONÇALVES (2000) mostraram que a fração de filme em um lavador Venturi tem alta dependência da razão $L / G$, sendo muito alta para pequenas razões L/G e diminuía com o aumento da razão L/G até um certo ponto onde voltava a crescer. Também, pode-se notar a pequena influência da mudança da velocidade do gás no perfil das curvas de formação de filme líquido. AZZOPARDI (1993) observou em seus experimentos que o comportamento da fração de filme em função da velocidade do gás para um lavador Venturi de diâmetro $10 \mathrm{~mm}$ se mostrou quase que constante.

A Tabela 3 mostra os pontos de mínima fração de filme para os quatro gráficos (a), (b), (c) e (d). A porcentagem de fração de filme indica o quanto do liquido injetado na garganta fica na parede do lavador e não é atomizado, sendo desejável sempre um valor pequeno de fração de filme para maior eficiência na limpeza do gás sujo.

Tabela 3 - Pontos de mínima fração de filme para cada gráfico

\begin{tabular}{|c|c|c|c|c|c|}
\hline \multirow{2}{*}{$\mathrm{D}_{\text {th }}$} & Gráfico & $\mathrm{V}_{\text {th }}(\mathrm{m} / \mathrm{s})$ & $\begin{array}{c}\text { Qtde de } \\
\text { orifícios }\end{array}$ & $\mathrm{L} / \mathrm{G}$ & $\begin{array}{c}\text { Fração de filme } \\
(\%)\end{array}$ \\
\hline \multirow{3}{*}{$40 \mathrm{~mm}$} & (a) & 26 & 4 & 0,5 & 24 \\
\cline { 2 - 6 } & (b) & 26 & 6 & 0,9 & 24 \\
\cline { 2 - 6 } & & 34 & 6 & 0,5 & 24 \\
\hline \multirow{2}{*}{$20 \mathrm{~mm}$} & (c) & 55 & 4 & 0,9 & 24 \\
\cline { 2 - 6 } & (d) & 55 & 6 & 0,9 & 35 \\
\hline
\end{tabular}

\section{CONCLUSÃO}

A fração de filme formada no lavador Venturi de garganta maior é fortemente influenciada pelas velocidades e configurações de orifícios avaliadas nesse estudo. A simples alteração da quantidade de orifícios de injeção faz com que a tendência das curvas de fração de filme em função do L/G seja invertida. Já o lavador Venturi de garganta menor apresenta curvas com comportamento semelhantes para todas as condições estudadas, tendo a tendência de diminuição da fração de filme ao se aumentar a penetração do jato, o L/G, e a vazão de líquido. Portanto, o diâmetro da garganta do lavador Venturi pode alterar o comportamento do equipamento quanto à deposição de filme líquido em suas paredes de maneira pouco previsível. 


\section{NOMENCLATURA}

$\mathrm{D}_{\text {th }}$ : Diâmetro da garganta do lavador Venturi (mm)

$>$ Ff: Fração de filme líquido (-)

$>$ L/G: razão entre a vazão de líquido injetado e a vazão de gás sujo $\left(\mathrm{L} / \mathrm{m}^{3}\right)$

$>\mathrm{V}_{\mathrm{th}}$ : Velocidade do gás na garganta $(\mathrm{m} / \mathrm{s})$

\section{REFERÊNCIAS}

AZZOPARDI, B.J. Liquid distribution in Venturi scrubbers: the importance of liquid films on the channel walls. Chemical Engineering Science, v.48, p. 2807-2813, Fevereiro, 1993.

BRASIL. Ministério do Meio Ambiente. Plano Nacional da Qualidade do Ar, 2009.

Disponível em: <http://www.mma.gov.br/cidades-sustentaveis/qualidade-do-ar>. Acesso em: 19 de abril de 2017.

BRASIL. Ministério do Meio Ambiente. Rede de Diagnostico de Monitoramento da Qualidade do Ar. Disponível em:

$<$ http://www.mma.gov.br/images/arquivo/80060/Diagnostico_Rede_de_Monitoramento_da_ Qualidade_do_Ar.pdf>. Acesso em: 19 de abril de 2017.

DAHER, M.A.F. Formação de filme líquido nas paredes de um lavador Venturi. Tese de mestrado - Universidade Federal de São Carlos, São Carlos, Brasil, 2008.

GONÇALVES, J. A. S. Aspectos da Modelagem Matemática de Lavadores Venturi. Tese de doutorado, Universidade Federal de São Carlos, São Carlos, Brasil, 2000.

GUERRA, V.G. Investigação do efeito da injeção de líquido por orifícios múltiplos na formação de gotas em um lavador Venturi. Tese de doutorado - Universidade Federal de São Carlos, São Carlos, Brasil, 2009.

GUERRA, A.P. Fração de filme em lavadores Venturi. Tese de mestrado - Universidade Federal de São Carlos, São Carlos, Brasil, 2010.

VISWANATHAN, S.; GNYP, A. W.; Pierre, C. C. Jet penetration measurements in Venturi Scrubber. Canadian Journal of Chemical Engineering, v. 61, p. 504-508, 1983. 